\title{
FEEDFORWARD LOAD TORQUE COMPENSATOR COMBINED WITH PI SPEED CONTROLLER FOR HIGH DYNAMIC PERFORMANCE OF PMSM DRIVES
}

\author{
Mohamed S. Zaky, Mahmoud A. Hassanien, and Skokry S. Shokralla \\ Electrical Engineering Dept., Faculty of Engineering, Minoufiya University, Shebin El- \\ Kom (32511), Minoufiya, Egypt, Mob. 002-0108265930; Fax: 002-0482235695, E-mail: \\ mszaky78@yahoo.com
}

\begin{abstract}
This paper presents a PI speed controller in conjunction with a feedforward load torque compensator in order to improve the dynamic performance of permanent magnet synchronous motor (PMSM) drives. The load torque estimator is used to provide a feedforward value in the speed controller in order to decouple the load torque from the speed control. This method can improve the PMSM dynamic performance against the disturbance torque without increasing the speed controller gain due to stability limitations. This can be achieved by dividing the electromagnetic torque in a feedforward value which should compensate the load torque, and a dynamic value which takes account of the speed variation. The load torque estimator compensates the speed control by setting a feedforward torque value through the q-axis current reference value. Therefore, the speed controller reaches immediately the speed reference value and a better response to load torque variations, which are detected and compensated leading to small speed variations, is obtained. The proposed controller with load torque compensator is examined through both simulation and experiments. The performance of IPMSM drive system with a conventional proportional-integral (PI) controller is presented in comparison with the proposed controller. The results show a significant improvement of the proposed controller, particularly during load torque variations and parameter variations.
\end{abstract}

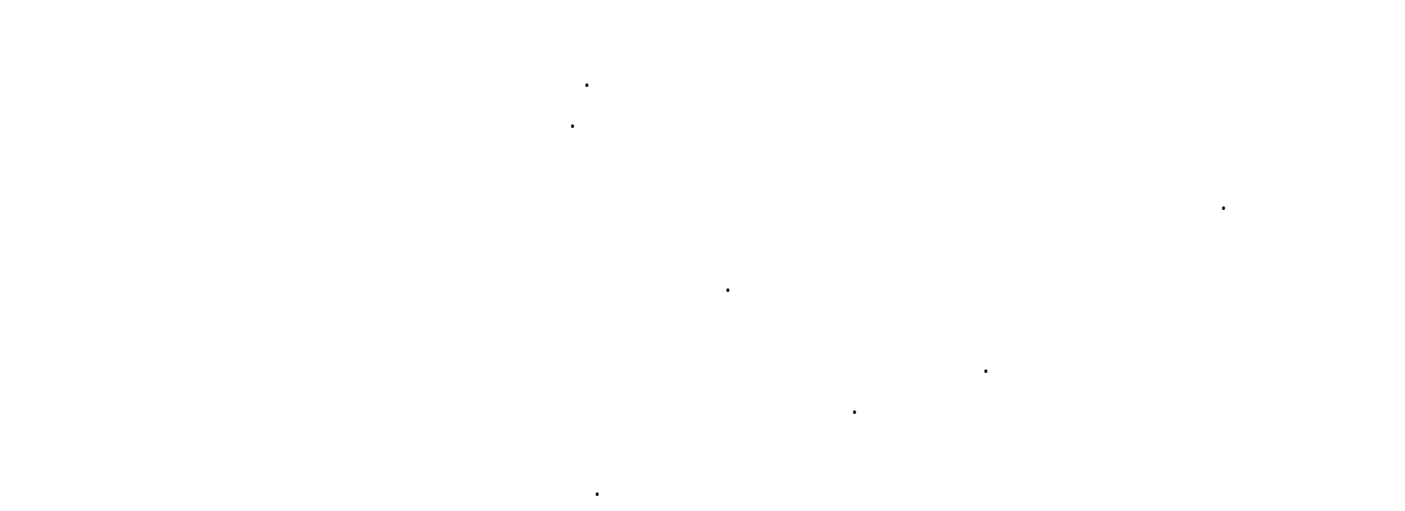

Keywords: Load torque estimator, permanent magnet synchronous motor, speed controller, field oriented control.

\section{INTRODUCTION}

Recent developments in power semiconductor technology, digital electronics, magnetic materials, and control algorithms have enabled modern ac motor drives to face challenging high-efficiency and high-performance requirements in the industrial applications. Among ac drives, the permanentmagnet synchronous motor has been becoming popular owing to its high torque to current ratio, 
large power to weight ratio, high efficiency, high power factor, and robustness [1-3].

Usually, high-performance motor drives used in robotics, rolling mills, machine tools, etc., require fast and accurate response, quick recovery from any disturbances, and insensitivity to parameter variations. The dynamic behavior of an ac motor can be significantly improved using vector control theory where motor variables are transformed into an orthogonal set of $\mathrm{d}-\mathrm{q}$ axes such that speed and torque can be controlled separately. This gives the interior permanent magnet synchronous motor (IPMSM) the highly desirable dynamic performance capabilities of a separately excited dc machine, while retaining the general advantages of the ac over dc motors [1].

In order to achieve high performance, the controller design of such a system plays crucial role in the system performance. The decoupling characteristics of a vector-controlled PMSM are adversely affected by the parameter changes. Traditionally, these control issues are handled by the conventional proportional-integral (PI) controller and other controllers [2-3]. However, parameter variations of the IPMSM leads to a cumbersome design approach for these controllers. In industrial applications, there are many uncertainties, such as system parameter uncertainty, external load disturbance, friction force, unmodeled uncertainty, etc. which always diminish the performance quality of the pre-design of the motor driving system.

Furthermore, the conventional fixed-gain PI and PID controllers are very sensitive to step change of command speed, parameter variations, and load disturbance [2-3]. Again, precise speed control of an IPMSM drive becomes a complex issue due to nonlinear coupling among its winding currents and the rotor speed as well as the nonlinearity present in the electromagnetic developed torque due to magnetic saturation of the rotor core [4].

For designing a high performance drives, gains have to be adapted to achieve fast transient response, accurate speed response, non-linear load handling capability and adaptability and quickest recovery from any kind of uncertainties. In vector control many works have been reported [4-12]. These include some simple and easy fixed gain control techniques such as proportional integral (PI), proportional integral differential (PID) control techniques [2-3]. On the other hand, many other different control techniques of varying degree of complexity have appeared on the nature of drive applications such as model reference adaptive controller (MARC) [5], sliding mode controller (SMO) [6], variable structure controller (VSC) [4], fuzzy logic controller (FLC) [7-10], neural network controller (NNC), neuro-fuzzy controller (NFC) [11] etc.
Although these fixed gain controller have been using in industry for a long time because of simplicity and ease to implement in real-time. However, conventional controllers such as PI, PID are not suitable for high performance drives. Since these controllers are very sensitive to plant parameter variations, load disturbance and any other kinds of disturbances.

To overcome such a limitation, feedforward load torque estimation parallel with speed controller is presented [12]. Feedforward compensator is an effective technique for industrial systems in operation, because the feedforward compensator only changes input of the system without requirement of changing the hardware of the system such as addition of sensors, which causes the increase of the cost of the systems.

Some systematic design methods for feedforward controllers have been proposed for special purposes [13-19]. A self-tuning control with load torque feedforward compensator for rolling mill dc drives has been presented. The feedback gains of an IP controller were adjusted by a pole placement using a recursive extended least squares (RELS) estimation algorithm [13]. A speed control of a PMSM using sliding mode control with load torque estimation has been presented [13]. The load disturbance is detected by the observer of an unknown and inaccessible input, and is compensated by the feedforward current. However, the controller in [18] suffers from low performance under parameter uncertainty, and not verified experimentally. A feedforward compensator for industrial articulated robot arms control systems through pole placement regulator has been presented [15]. Speed control of brushless dc motor drives by load torque estimation has been presented [16]. In this work, the proportional gain vector design is by trial and error, and the controller was not verified experimentally. Multidimensional feedforward compensator for industrial systems through pole placement regulator and state observer has been proposed [17]. Variable structure control with feedforward compensator for robotic manipulator under load uncertainties has been presented [18]. Online load torque compensator for a single rolling piston compressor has been presented [19]. This method depends on separating each speed ripple harmonics order and compensates each term independently with injecting each harmonic compensation torque values.

The main objective of this paper is to modify the PI speed controller using feedforward load torque estimator for high dynamic performance PMSM drives. The load torque estimator is used to provide a feedforward value in the speed controller in order to decouple the load torque from the speed control. This can be achieved by dividing the electromagnetic torque in a feedforward value which should 
compensate the load torque, and a dynamic value which takes account of the speed variation. The proposed controller with load torque compensator is examined through both simulation and experiments in comparison to the conventional PI controller. An excellent speed response under load torque variations and parameter uncertainty is achieved.

\section{Field Oriented Model of PMSM}

The model of a PMSM can be described by the following equations in the d-q synchronously rotating reference frame as [1]:

$$
\begin{aligned}
& \frac{d i_{q}}{d t}=-\frac{R_{s}}{L_{q}} i_{q}-\frac{L_{d}}{L_{q}} \omega_{r} i_{d}+\frac{1}{L_{q}} V_{q}-\frac{\lambda_{m}}{L_{q}} \omega_{r} \\
& \frac{d i_{d}}{d t}=-\frac{R_{s}}{L_{d}} i_{d}+\frac{L_{q}}{L_{d}} \omega_{r} i_{q}+\frac{1}{L_{d}} V_{d}
\end{aligned}
$$

The developed torque can be expressed as

$T_{e}=\frac{3}{2} \frac{P}{2}\left[\lambda_{m} i_{q}^{*}+\left(L_{d}-L_{q}\right) i_{d}^{*} i_{q}^{*}\right]$

and the motor dynamics can be represented by

$T_{e}=\frac{J}{P} \frac{d \omega_{r}}{d t}+\frac{B}{P} \omega_{r}+T_{l}$

\section{Feedforward Load Torque Compensator}

In this section, the load torque estimator is defined and it is applied to the speed control loop as feedforward path.

\subsection{Load Torque Estimation}

The proposed speed control method requires information of the load torque for feedforward compensation. A direct measurement of the load torque is difficult because other high cost equipment is required. Therefore, this paper used to estimate value by the state observer. Input value of the state observer is position information of rotor.

The electromagnetic torque is given by the following equations, where the friction torque is part of the load torque.

$\frac{J}{P} \frac{d \omega}{d t}=T_{e}-T_{l}$
The control principle of a IPMSM drive is based on a field oriented control method. For PM rotor, the flux $\lambda_{m}$ is constant. In (3), if $i_{d}=0$, the electromagnetic torque is then proportional to $i_{q}$, which is determined by closed-loop control. Since the generated motor torque is linearly proportional to the $q$-axis current, as $\lambda_{m}$ is constant in (3), the maximum torque per ampere can be achieved.

Thus, the developed torque in (3) can be expressed as

$T_{e}=K_{t} i_{q s}^{*}$

where

$K_{t}=\frac{3}{2} \frac{P}{2} \lambda_{m}$

The estimator should be used to provide a feedforward value in the speed controller in order to decouple the load torque from the speed control. The electromagnetic torque is divided in a feedforward value $T_{e T_{l}}$ which should compensate the load torque $T_{l}$, and a dynamic value $T_{e \Delta \omega}$ which takes account of the speed variation.

Thus, equation (5) can be rewritten as

$T_{e}=T_{e T_{l}}+T_{e \Delta \omega}=T_{l}+\frac{J}{P} \frac{d \omega_{r}}{d t}$

where,

$$
\begin{aligned}
& T_{e T_{l}}=T_{l} \\
& T_{e \Delta \omega}=\frac{J}{P} \frac{d \omega_{r}}{d t}
\end{aligned}
$$

Therefore, the speed controller provides $T_{e \Delta \omega}$ for speed control and the feedforward path provides $T_{e T_{l}}$ for load torque compensation. However, the electrical torque is not directly known, but it is proportional to the q-axis current and can be calculated. The load torque can be estimated with the calculated electrical torque and the variation of the motor speed.

$$
\hat{T}_{l}=T_{e T_{l}}=T_{e}-T_{e \Delta \omega}=\frac{3}{2} \frac{P}{2} \lambda_{m} i_{q s}^{*}-\frac{J}{P} \frac{d \omega_{r}}{d t}
$$




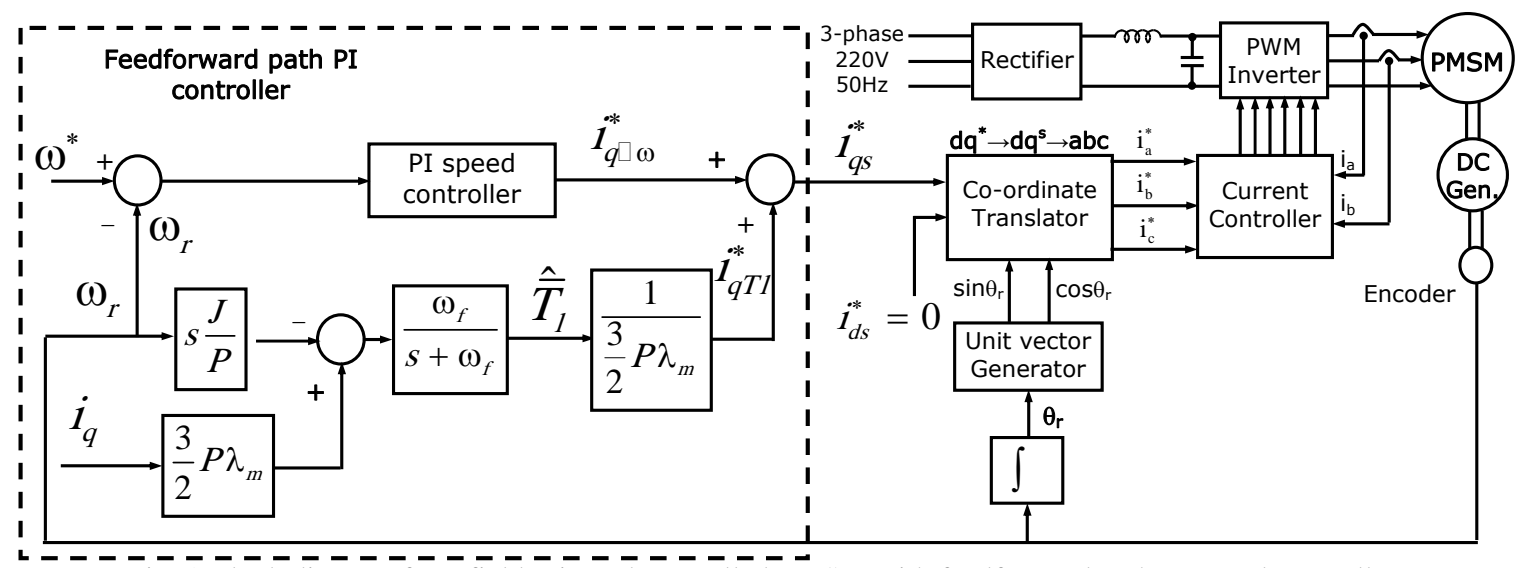

Fig. 1 Block diagram for a field oriented controlled PMSM with feedforward path PI speed controller.

\subsection{Filter Structure}

The disturbance dependence of the estimate $\hat{T}_{I}$ can be reduced using a filter. In order to achieve the required fast execution time a first order filter has been used. It is designed to reduce disturbances frequencies in the order of the sampling frequency.

In the literature many filter structures can be found, a fairly convenient for discrete filtering is shown in this section. It is a first order filter structure and is mainly employed for estimation issues.

The principle of this structure is the calculation of the error, i.e. difference between the actual value $\hat{T}_{l}[k]$ and the last filtered value $\hat{T}_{l}[k-1]$.

$e[k]=\hat{T}_{l}[k]-\hat{T}_{l}[k-1]$

The filtered value is generated by integration of the error, i.e. the error is used to update the output value. Integration means in the discrete domain summation and multiplication with the sampling period $T_{s} . \hat{\bar{T}}$ is the filtered value and $\omega_{f}$ is a coefficient which determines the bandwidth of the structure.

$$
\hat{T}_{l}[k]=\omega_{f} T_{s} \sum_{i=0}^{k} e[i]
$$

\subsection{Feedforward Term}

The modification of reference input to generate an actual input is an effective and easily applicable technique to improve the control performance of industrial systems because it does not demand to rearrange the hardware of the systems such as the addition of sensors, which causes the increase of the cost of the systems.

The speed controller sets the torque indirectly by giving a current reference value on the q-axis. For this reason the estimator has to provide the reference current $i_{q T_{I}}^{*}$ which is added to the PI-controller output $i_{q \Delta \omega}^{*}$ i.e. the total reference current is $i_{q s}^{*}=i_{q T_{I}}^{*}+i_{q \Delta \omega}^{*}$.

$$
i_{q T_{l}}^{*}=\frac{\hat{\bar{T}_{l}}}{\frac{3}{2} \frac{P}{2} \lambda_{m}}
$$

According to the mathematical model given above, the block diagram of a speed control for PMSM drive system can be represented as shown in Fig. 1. The structure of the modified speed controller, i.e. the PI controller with feedforward path is also shown in Fig. 1. Moreover, the block diagram of the load torque, i.e. the feedforward path structure is shown. The maximum current and the corresponding maximum torque are limited at the controller output $i_{q}^{*}$ to its nominal value.

In order to meet stability and robustness criteria, the feedforward value should not act with a larger bandwidth than speed controller. For this reason, the factor $\omega_{f}$ which sets the bandwidth must be chosen accordingly.

\section{Simulation Results}

The block diagram of FOC as well as the proposed speed controller with the feedforward load torque compensator, shown in Fig. 1, is built using Matlab/Simulink software package for the PMSM parameters as given in Table 1.

\subsection{Load Torque Disturbances}

The FOC drive system is examined during sudden load change to test the robustness of the modified speed controller with feedforward load torque compensator under load torque variations. Fig. 3 shows the responses of the motor speed, the developed torque, the stator currents and the $\mathrm{d}-\mathrm{q}$ currents under sudden removal and application of load torque $3 \mathrm{~N} . \mathrm{m}$ at $t=0.8 \mathrm{sec}$ and $t=1.2 \mathrm{sec}$, respectively. The figure is presented for the proposed controller with the feedforward load torque compensator in comparison with the conventional PI speed controller. It is observed from Fig. 3(b) that the estimated torque reaches the load torque smoothly. Furthermore, the motor speed recovers quickly to the steady state value under load torque variations with 
small speed variations. This is because the feedforward load torque compensator modifies the current reference value $i_{q s}^{*}$ to compensate quickly the variations of speed due to the load torque variations. However, the speed error is large and takes a longer time to reach the steady state speed using fixed PI controller as shown in Fig. 3(a).

The effectiveness and the robustness of the proposed speed controller are also tested during repetitive torque variations. Fig. 4 shows the simulated responses for repetitive torque variations. It is obvious that the estimated torque follows the torque command quickly. Moreover, the motor speed follows the reference speed and recovers quickly under the repetitive torque command. However, the speed response with the conventional PI controller is slower and takes large time to reach the steady state value.

The speed responses at different operating conditions are presented with a comparison between the conventional PI controller and the modified controller with feedforward load torque compensator. Figs. from 5 to 8 show a comparison between motor speed with conventional PI controller and the proposed controller with feedforward load torque compensator. It found that overshoot for PI controller is less than for feedforward path PI controller but feedforward path reach to steady state faster in case of load and no-load. The superiority of the proposed feedforward path PI controller is observed during starting at low speed with loading conditions as shown in Fig. 6(b). Figs. 7 and 8 show the simulated speed responses with conventional PI controller and feedforward path PI controller. It is observed that the feedforward path PI controller is better than the conventional PI controller since it reaches faster to steady state value under sudden change of load torque.

\subsection{Effect of parameters variations}

In order to test the robustness of the proposed FOC, the response of the motor is simulated for three different inertias with the conventional PI controller and compared with feedforward path PI controller at the same conditions. Fig. 9 shows the simulated speed responses under motor inertias of $\mathrm{J}=\mathrm{J}_{0}=0.005$ kg. $\mathrm{m}^{2}, \mathrm{~J}=0.5 \mathrm{~J}_{0}=0.0025 \mathrm{~kg} \cdot \mathrm{m}^{2}, \mathrm{~J}=2 \mathrm{~J}_{0}=0.01 \mathrm{~kg} \cdot \mathrm{m}^{2}$. It can be observed that the speed response of feedforward path PI controller is better than the corresponding one using conventional PI controller in terms of small rising time and small settling time.

The IPMSM drive system with the proposed feedforward path PI controller is tested under speed reversal at no-load conditions as shown in Fig. 10. It is obvious that the speed track the reference one smoothly.
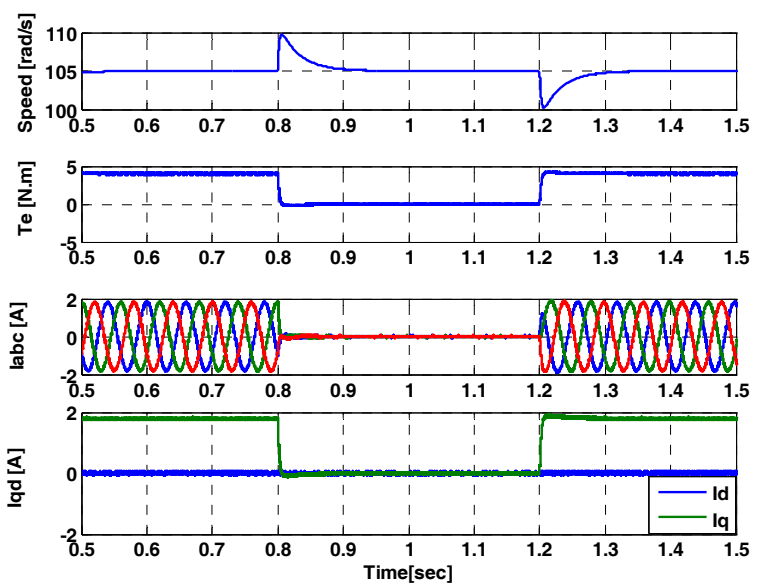

(a) with PI controller
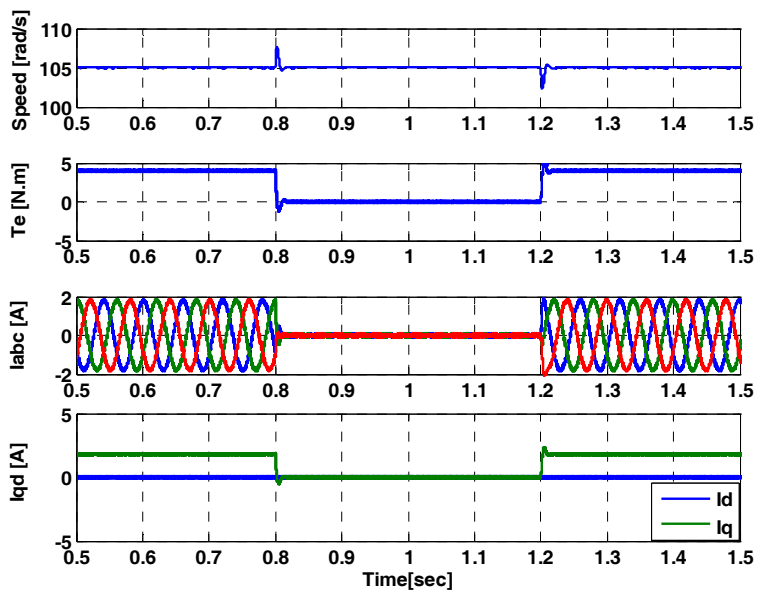

(b) with feedforward path PI controller

Fig. 3 Simulated responses during removal and application of load torque of $4 \mathrm{Nm}$ and speed reference of $105 \mathrm{rad} / \mathrm{s}$.
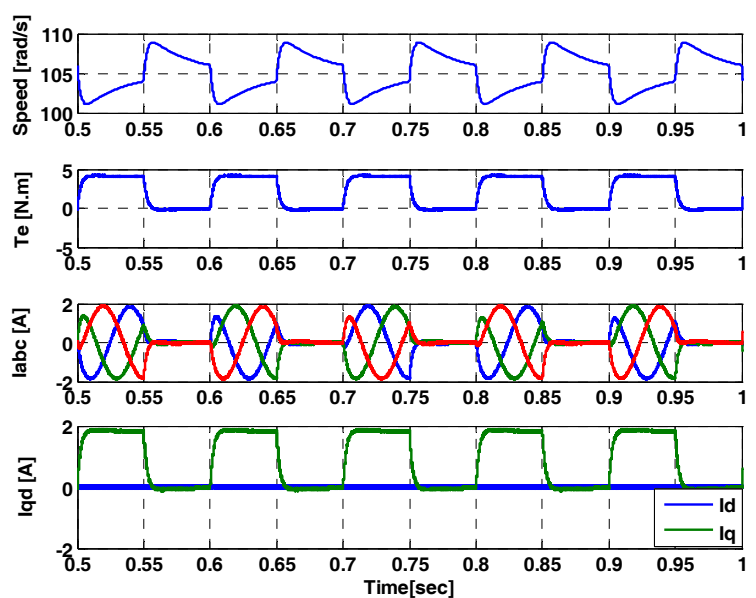

(a) with PI controller 
Mohamed S. Zaky, Mahmoud A. Hassanien, and Skokry S. Shokralla, "FeedForward load torque ..."
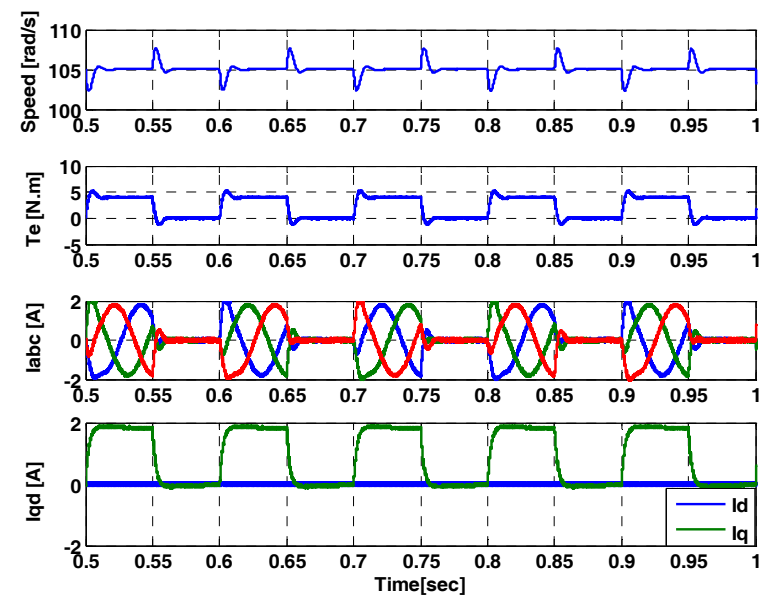

(b) with feedforward path PI controller

Fig. 4 Simulated responses during repetitive load torque variations of $4 \mathrm{Nm}$ at $105 \mathrm{rad} / \mathrm{s}$ with conventional PI controller and feedforward path PI controller.

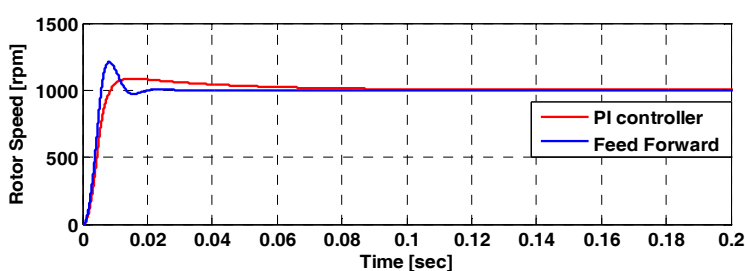

Fig. 5 Simulated speed responses with conventional PI controller and feedforward path PI controller under load torque of $3 \mathrm{~N} . \mathrm{m}$ and speed reference of $1000 \mathrm{rpm}$.

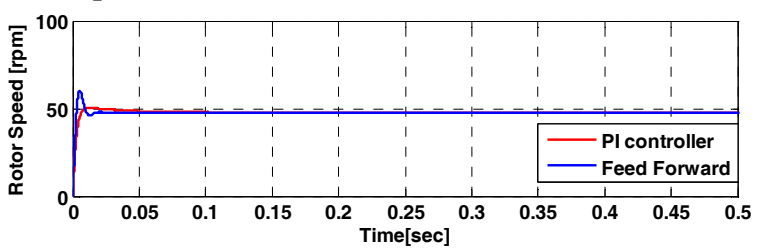

(a)

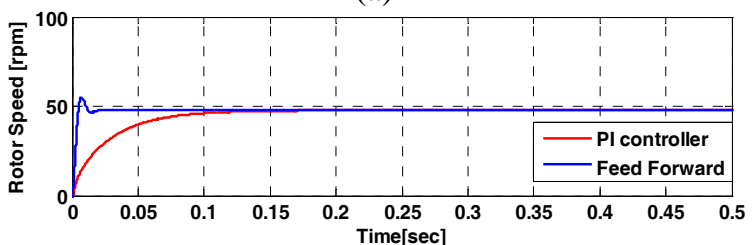

(b)

Fig. 6 Simulated speed responses with conventional PI controller and feedforward path PI controller (a) with no-load condition and speed reference of 5 $\mathrm{rad} / \mathrm{s}$; (b) with load torque of $3 \mathrm{~N} . \mathrm{m}$ and speed reference of $1000 \mathrm{rpm}$.

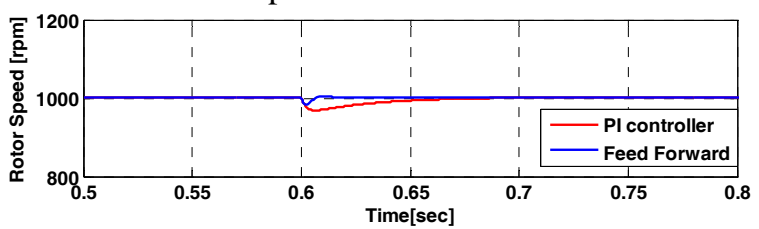

Fig. 7 Simulated response under suddenly load and $1000 \mathrm{rpm}$.

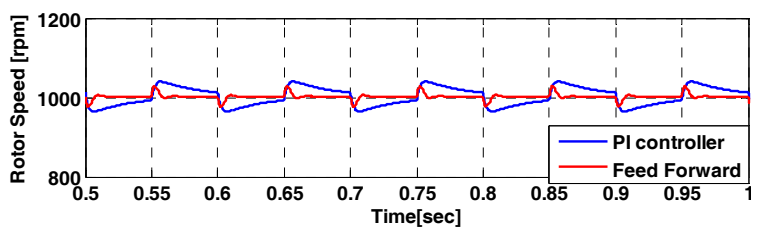

Fig. 8 Simulated response under fluctuation torque and $1000 \mathrm{rpm}$.

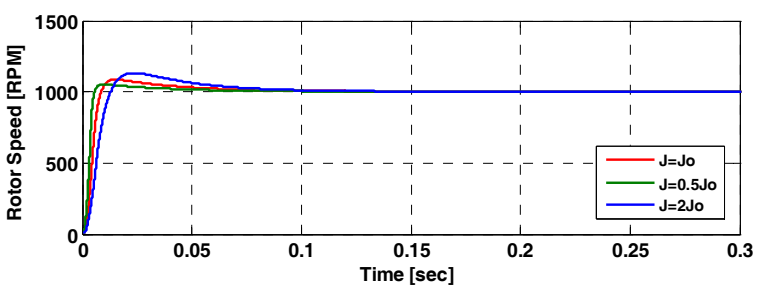

(a) with conventional PI controller

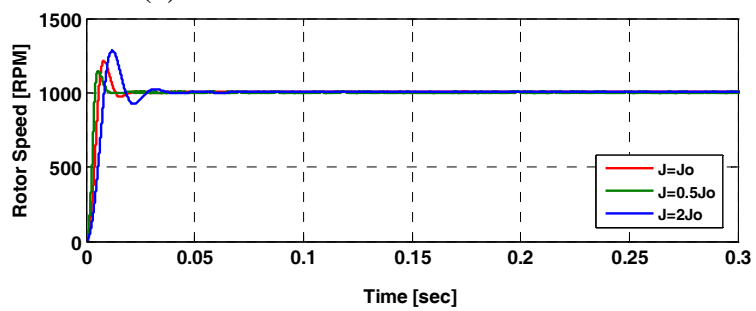

(b) with feedforward path PI controller.

Fig. 9 Simulated speed responses with conventional PI controller and feedforward path PI controller under motor inertia variations $\left(J=J_{o}, J=0.5 J_{o}, J=\right.$ $2 J_{o}$ ).
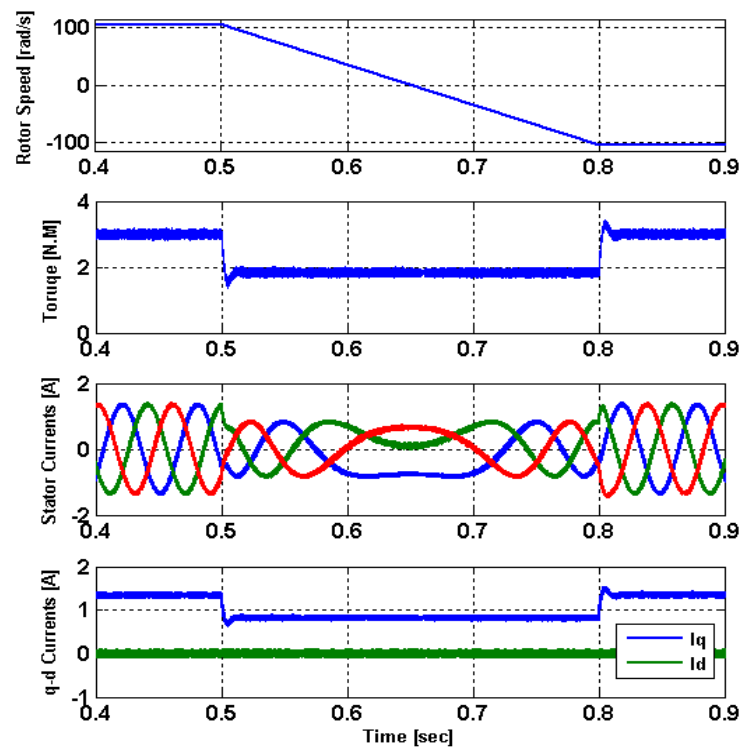

Fig. 10 Simulated responses during speed reversal under no load condition with feedforward load torque compensator. 


\section{Experimental results}

In order to investigate the performance of the proposed controller, laboratory experiments are carried out on a dSPACE DS1102 DSP-board-based PMSM drive system. The block diagram of the experimental system is shown in Fig. 11. The specifications of the motor used in experiments are given in the Appendix.

The DSP-board is installed in a Pentium II PC. The control algorithm developed in Sections 2 and 3 is built in Simulink environment and is executed within sampling time by the DS-1102 board main processor (TMS320C31) in real-time. The board is used for PWM signal generations, current signal collection and speed calculation from position feedback. The optical incremental encoder coupled to the rotor can generate 2048 pulses per revolution of the rotor. The IPMSM is supplied by a three-phase voltage-source PWM inverter, which is composed of six IGBT's and a gate driver board. A dc power supply is used to supply the inverter with a maximum voltage of $500 \mathrm{~V}$ and a current of $5 \mathrm{~A}$. The motor phase currents are measured by using LA NP-25 mounted hall-effect current sensors and these signals are in turn sent to the DS1102 board analog-to-digital (A/D) ports for current control and PWM pulses generation.

Fig. 12 shows the experimental starting speed responses of the drive system using conventional PI controller and the feedforward path PI controller, respectively. It is obvious that the proposed controller gives better responses in terms of fast response. This figure shows also the experimental speed responses with step change in reference speed for the conventional PI and the proposed one, respectively. It is clear that the proposed controller can handle the sudden change in reference speed quickly without overshoot, undershoot, or steadystate error, whereas the PI-controller-based drive system has an overshoot and the response is not as fast as that of the modified speed controller.

Performance of the PMSM drive system with the different speed controllers is also evaluated and tested under sudden change of load. The experimental speed and stator current results with step applying the load are shown in Fig. 13 for the conventional PI controller and the proposed PI speed controller with feedforward load torque compensator, respectively. There is a big dip in the speed with sudden applying the load using the PI speed controller as shown in Fig. 13(a). Moreover, the speed response takes a longer time to reach the steady-state speed using the PI speed controller. Whereas the proposed PI speed controller with feedforward load torque compensator takes a lower time to reach the steady-state speed, Fig. 13(b). Thus, the proposed PI speed controller with feedforward load torque compensator has been found to be better than the conventional PI-controller-based system and, hence, it is a robust controller for highperformance industrial drive applications.

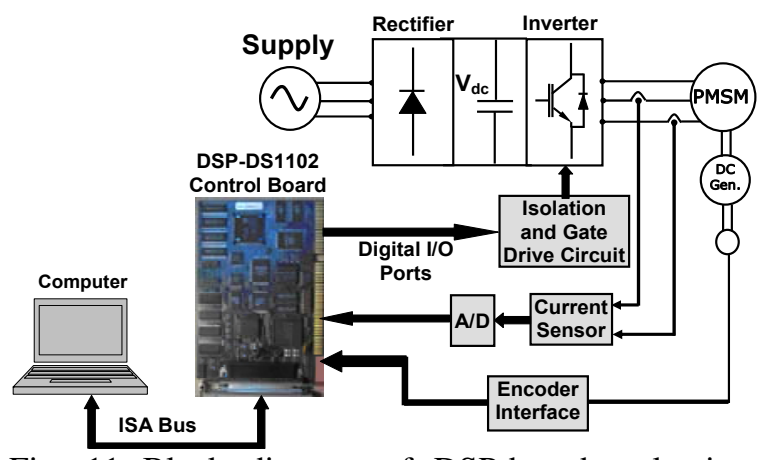

Fig. 11 Block diagram of DSP-based real- time implementation of control algorithms for PMSM drive system.

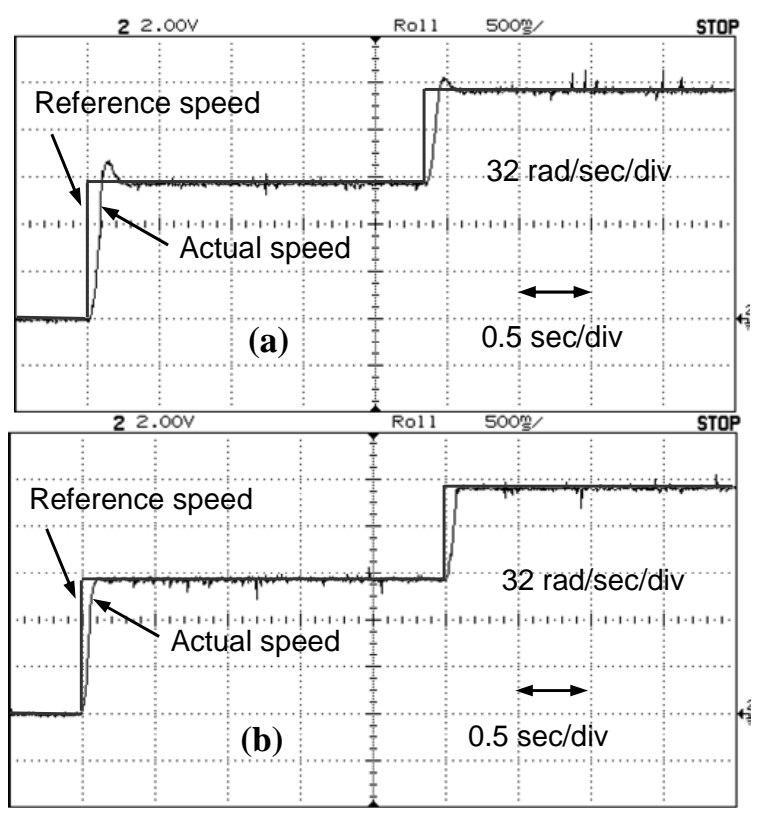

Fig. 12 Experimental speed response of the PMSM drive for starting and sudden change of reference speed (a) with PI speed controller (b) with modified speed controller using load torque compensator.

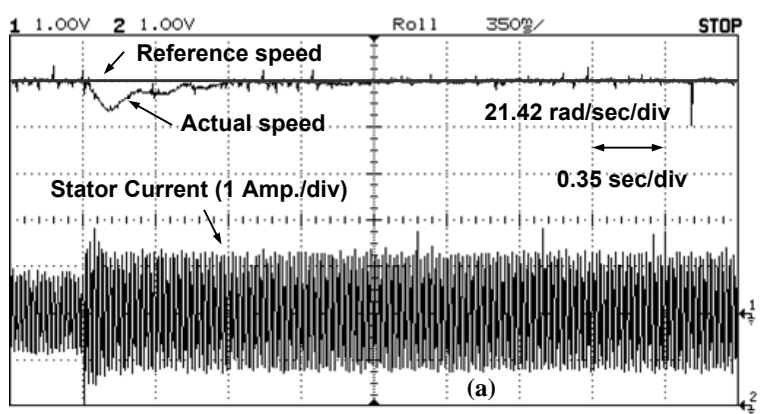




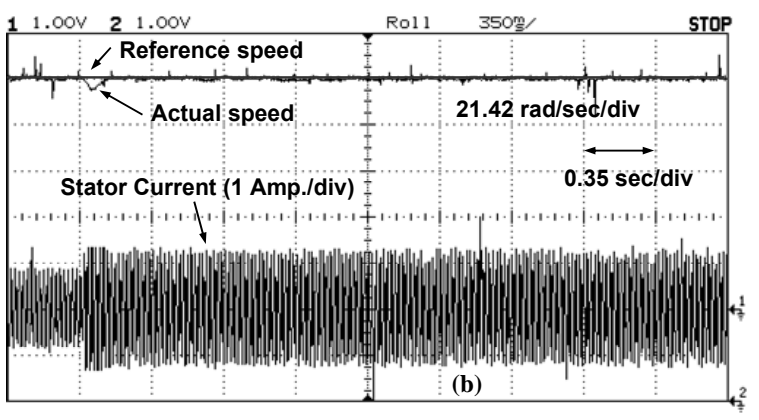

Fig. 13 Experimental speed and stator current responses of the PMSM drive during sudden change of load torque $1 \rightarrow 3$ N.m (a) with PI speed controller (b) with modified speed controller using load torque compensator.

\section{Conclusion}

The proposed PI speed controller with feedforward load torque compensator with field oriented control of a IPMSM drive has been successfully implemented in real time. The validity of the proposed control technique has been examined and assessed experimentally and by computer simulation under different operating conditions. Performance of the proposed controller with feedforward load torque compensator has been found more robust as compared to the conventional PI-controller-based system. It has been observed that the PI controller suffers from overshoot and takes a longer time to reach the steady state. However, the modified speed controller takes a shorter time to reach the steady state smoothly despite parameter uncertainty and load torque variations. Also, the actual speed has a very small change during the load disturbance and recovers quickly. Consequently, the developed PI speed controller with feedforward load torque compensator has robust speed characteristics against parameters and disturbance torque variations. Therefore, it can be adapted speed control for highperformance PMSM motor without increasing the speed controller gain.

\section{APPENDIX}

\section{A. List of symbols}

$\begin{array}{ll}\mathrm{v}_{\mathrm{d}}, \mathrm{v}_{\mathrm{q}} & \mathrm{d} \text { and q-axes stator voltages; } \\ \mathrm{i}_{\mathrm{d}}, \mathrm{i}_{\mathrm{q}} & \mathrm{d} \text { and q-axes stator currents; } \\ \mathrm{R}_{\mathrm{s}} & \text { stator resistance; } \\ \mathrm{L}_{\mathrm{d}}, \mathrm{L}_{\mathrm{q}} & \mathrm{d} \text { and q-axes stator inductances; } \\ \mathrm{T}_{\mathrm{e}}, \mathrm{T}_{\mathrm{L}} & \begin{array}{l}\text { electromagnetic and load torques; } \\ \mathrm{J}_{\mathrm{o}}\end{array} \\ \text { load; } & \text { moment of inertia of the motor and } \\ \mathrm{B} & \text { friction coefficient of the motor; } \\ \mathrm{P} & \text { number of poles of the motor; } \\ \omega_{\mathrm{r}} & \text { rotor speed in angular frequency; } \\ \lambda_{\mathrm{m}} & \text { rotor magnetic flux linkage. }\end{array}$

\section{B. Motor and Controller Parameters}

Table I Permanent Magnet Synchronous Motor Parameters

\begin{tabular}{|l|c|l|c|}
\hline Rated power (HP) & 1 & $\mathrm{R}_{\mathrm{s}}$ & $3.7 \mathrm{Ohm}$ \\
\hline Rated voltage (Volt) & $220 \mathrm{~V}$ & $\mathrm{~L}_{\mathrm{d}}$ & $30 \mathrm{mH}$ \\
\hline Phase current (Amp.) & 1.6 & $\mathrm{~L}_{\mathrm{q}}$ & $38 \mathrm{mH}$ \\
\hline Rated Speed (rpm) & 1000 & $\lambda_{\mathrm{m}}$ & $0.495 \mathrm{~V} . \mathrm{S} / \mathrm{Rad}$ \\
\hline Number of poles & 6 & $\mathrm{~J}_{\mathrm{o}}$ & $5 \mathrm{e}^{-3} \mathrm{Kg} \cdot \mathrm{m}^{2}$ \\
\hline Rated Frequency & $50 \mathrm{~Hz}$ & $\begin{array}{l}\text { Rated } \\
\text { torque }\end{array}$ & $5 \mathrm{~N} . \mathrm{m}$ \\
\hline
\end{tabular}

Table II Gains of Conventional PI Speed Controller \begin{tabular}{|l|l|}
\hline Proportional gain & \\
\hline Integral gain & \\
\hline
\end{tabular}

$\omega_{f}=500$

\section{REFERENCES}

[1] M. S. Zaky, "Robust Speed Control of Permanent Magnet Synchronous Motor Drives," In Proc. of $13^{\text {th }}$ International Middle-East Power Systems Conference (MEPCON'2009), Assiut University, Assiut, Egypt, pp. 316-321, Dec. 20-23, 2009.

[2] B. K. Bose, P. M. Szezesny, “A microcomputerbased control and simulation of an advanced IPM synchronous machine drive system for electric vehicle propulsion,” IEEE Transactions on Industrial Electronics, vol. 35, no. 4, Nov. 1988, pp. 547-559.

[3] P. Pillay and R. Krishnan, "Control characteristics and speed controller design for a high performance permanent magnet synchronous motor drive, “ In Proc. IEEE PESC, 1987, pp. 598-606.

[4] M. S. Zaky, "Adaptive Switching Plane of IVSC for Speed Control of Permanent Magnet Synchronous Motor Drives" Electric Power Components and Systems, vol. 39, issue 13, pp. 1353-1372, August 2011.

[5] F. Betin, D. Pinchon, and G. A. Capolino, A time-varying sliding surface for robust position control of a DC motor drive, IEEE Trans. on Ind. Electron., 49 (2) (2002) 462-473.

[6] K. K. Shyu, C. K. Lai, Y. W. Tsai, and D. I. Yang, A newly robust controller design for the position control of permanent-magnet synchronous motor, IEEE Trans. on Ind. Electron., 49 (3) (2002) 558- 565.

[7] M. N. Uddin, M. A. Abido, M. A. Rahman, Development and implementation of a hybrid intelligent controller for interior permanentmagnet synchronous motor drives, IEEE Trans. Ind. Appl. 40 (1) (2004) 68-76.

[8] M. N. Uddin, T. S. Radwan, M. A. Rahman, Fuzzy-logic-controller-based cost-effective 
Mohamed S. Zaky, Mahmoud A. Hassanien, and Skokry S. Shokralla, "FeedForward load torque ..."

four-switch three-phase inverter-fed IPM synchronous motor drive system, IEEE Trans. Ind. Appl. 42 (1) (2006) 21-30.

[9] R. S. Rebeiro and M. N. Uddin, "FLC based tuned PI controller for wide speed range operation of IPMSM drive," IEEE Power and Energy Society General Meeting, 25-29 July 2010, pp. 1-5.

[10] M. Nasir Uddin and Ronald S. Rebeiro, "Neurofuzzy and fuzzy logic controllers based speed control of IPMSM drive-A torque ripple optimization approach," 36th Annual Conference on IEEE Industrial Electronics Society IECON 2010, pp. 2242-2247.

[11] Ying-Shieh Kung, and Ming-Hung Tsai, "FPGA-based speed control IC for PMSM drive with adaptive fuzzy control," IEEE Transactions on Power Electronics, Vol. 22, No. 6, November 2007, pp. 2476- 2486.

[12] Preindl, M.; Schaltz, E.; Load torque compensator for Model Predictive Direct Current Control in high power PMSM drive systems," IEEE International Symposium on Industrial Electronics (ISIE), 2010, pp. 1347 1352.

[13] Jun-Keun Ji, and Seung-Ki Sul, "DSP-Based Self-Tuning IP Speed Controller with Load Torque Compensation for Rolling Mill DC Drive," IEEE Transactions On Industrial Electronics, Vol. 42, No. 4, pp. 382-386, August 1995.

[14] Mun-Soo Kim , Dall-Sup Song, Yong-Kil Lee, Tae-Hyun Won, Han-Woong Park, Yong-I1
Jung, Man Hyung Lee, “A Robust Control of Permanent Magnet Synchronous Motor Using Load Torque Estimation,” ISIE 2001, Pusan, KOREA, pp. 1157-1162, 2011.

[15] Satoru Goto, Masatoshi Nakamura and Masayuki Obata, "Feedforward Compensator for Control Systems through Pole Assignment Regulator,” 2000 IEEE, pp. 1791-1796.

[16] Ki-Hong Park, Tae-Sung Kim, Sung-Chan Ahn, Dong-Seok Hyun,” Speed Control of HighPerformance Brushless DC Motor Drives by Load Torque Estimation,” 2003 IEEE, pp. 1677-1681.

[17] Satoru Goto, and Masatoshi Nakamura, "Multidimensional Feedforward Compensator for Industrial Systems through Pole Assignment Regulator and Observer," IEEE Transactions on Industrial Electronics, Vol. 53, No. 3, June 2006, pp. 886-894.

[18] Suolin Duan Lanping Chen Zhenghua Ma, Guirong Lu, Lanping Chen, "Variable Structure Control with Feedforward Compensator for Robot Manipulators Subject to Load Uncertainties,” $11^{\text {th }}$ Int. Conf. control, Automation, Robotics and Vision, Singapore, 710th December 2010, pp. 2367-2372, ICARCV2010.

[19] Bon-Gwan Gu1, Jun-Hyuk Choi1, and InSoung Jung1, "Online Load Torque Compensator for Single Rolling Piston Compressor," $8^{\text {th }}$ International Conference on Power Electronics - ECCE Asia, May 30-June 3, 2011, The Shilla Jeju, Korea, pp. 2720-2724. 